\title{
GERMINAÇÃO DE SEMENTES DE ALFACE SUBMETIDAS A CONDICIONAMENTO OSMÓTICO DURANTE O ARMAZENAMENTO
}

\author{
Simone Aparecida Fessel ${ }^{1,4 *}$; Roberval Daiton Vieira ${ }^{2,5} ;$ Teresinha de Jesus Deléo Rodrigues ${ }^{3}$; \\ Marcelo Fagioli ${ }^{1}$ \\ ${ }^{1}$ Pós-Graduandos em Agronomia - Produção e Tecnologia de sementes - FCAV/UNESP. \\ ${ }^{2}$ Depto. Produção Vegetal - FCAV/UNESP, Via de Acesso Prof. Paulo Donato Castellane, s/n, CEP: 14884-000, \\ Jaboticabal, SP. \\ ${ }^{3}$ Depto. Biologia Aplicada à Agropecuária- FCAV/UNESP. \\ ${ }^{4}$ Bolsista FAPESP. \\ ${ }^{5}$ Bolsista CNPQ. \\ *Autor correspondente <sifessel@fcav.unesp.br>
}

RESUMO: Em algumas espécies a técnica do condicionamento osmótico permite a obtenção de uma germinação rápida e uniforme. A pesquisa teve por objetivo verificar a eficiência do condicionamento osmótico de sementes de alface sobre a sua germinação. Sementes dos cultivares Mesa 659, Nabuco RS e Verônica, com dois níveis de viabilidade, foram submetidas ao condicionamento osmótico em solução $(0,35$ mol) de manitol por períodos de $3,4,5$ e 6 dias sob $20^{\circ} \mathrm{C}$ e em presença de luz. A seguir, as sementes foram submetidas à secagem $\left(32^{\circ} \mathrm{C}\right)$ por 12 horas em estufa com circulação de ar. As avaliações foram feitas pelo teste padrão de germinação aos $0,10,20,30,60$ e 90 dias após o condicionamento e secagem das sementes. Utilizou-se o delineamento experimental inteiramente casualizado, com quatro repetições de 50 sementes, em esquema fatorial $2 \times 5 \times 6$, (dois níveis de vigor; cinco períodos de condicionamento osmótico e seis períodos de armazenamento após secagem). A resposta de sementes de alface ao condicionamento osmótico varia em função do cultivar e do período de condicionamento osmótico.

Palavras- chave: Lactuca sativa, manitol

\section{GERMINATION OF LETTUCE SEEDS SUBMITTED TO OSMOTIC PRIMING DURING STORAGE}

\begin{abstract}
In some species the osmopriming technique allows rapid and uniform germination of seeds. This research studies the efficiency of osmopriming on the germination of lettuce seeds. Seeds of the cultivars Mesa 659, Nabuco RS and Verônica were osmoprimed with a mannitol solution $(0.35 \mathrm{~mol})$ for periods of 3,4 , 5 , and 6 days, at the temperature of $20^{\circ} \mathrm{C}$ and under daylight. After priming seeds were dried for 12 hours in an oven at $32^{\circ} \mathrm{C}$. Evaluation of osmopriiming efficiency was performed by the standard germination test $0,10,20$, 30,60 and 90 days after priming, in a complete randomized design with four replications, 50 seeds per replicate. Data were submitted to analysis of variance in a factorial arrangement $2 \times 5 \times 6$ ( 2 levels of vigor; 5 periods of osmopriming and 6 periods of storage after drying). The effect of osmopriming on lettuce seeds varied depending on the cultivar and priming period.
\end{abstract} Key words: Lactuca sativa, mannitol

\section{INTRODUÇÃO}

Em espécies de ciclo curto, o período compreendido entre a semeadura e a emergência das plântulas representa uma fase crítica para o cultivo, de modo que a uniformidade e a porcentagem de emergência de plântulas assumem importância na produção e na qualidade do produto obtido (Eira \& Marcos Filho, 1990).

Um dos sintomas do declínio da qualidade fisiológica é a redução da velocidade de germinação, representada pelo aumento do período decorrido entre a germinação da primeira e da última semente de um lote, e consequentemente, pela desuniformidade de desenvolvimento entre as plântulas de um mesmo lote (Eira \& Marcos Filho, 1990).
Várias técnicas têm sido propostas para reduzir o tempo necessário entre a semeadura e a emergência das plântulas, bem como aumentar a tolerância das sementes às condições adversas existentes nesse período; assim o condicionamento osmótico das sementes, proposto por Heydecker \& Gibbins (1978), entre outras tecnologias, consiste em um pré-tratamento no qual as sementes são condicionadas em solução osmótica por períodos de tempo e temperaturas determinados (Khan et al.,1978). O potencial osmótico da solução regula a hidratação das sementes, permitindo a ativação de processos metabólicos nas fases iniciais da germinação e, paralelamente, evitando a emergência da radícula (Bradford, 1986; Khan, 1992).

Segundo McDonald (1998) o condicionamento osmótico constitui uma alternativa viável para favorecer 
o aumento no desempenho das sementes no campo, particularmente sob condições adversas, principalmente em lotes com baixa qualidade fisiológica.

Assim, conduziu-se o presente estudo com o objetivo de avaliar a eficiência do condicionamento osmótico em sementes de alface sobre sua germinação no decorrer do armazenamento.

\section{MATERIAL E MÉTODOS}

O estudo foi realizado no Laboratório de Análise de Sementes, do Departamento de Produção Vegetal da Faculdade de Ciências Agrárias e Veterinárias, UNESP - Câmpus de Jaboticabal, SP, usando-se sementes de alface dos cultivares Mesa 659 (Asgrow), Nabuco RS (Royal Sluis) e Verônica (Agroflora), durante o período de março a outubro de 1997.

Após a recepção, as sementes foram retiradas da embalagem hermética, homogeneizadas, colocadas em embalagem porosa (sacos de papel Kraft) e mantidas em condições ambientais não controladas do laboratório.

Para obtenção de lotes com diferentes níveis de vigor, uma amostra de cada um dos lotes foi submetida ao envelhecimento artificial $\left(42^{\circ} \mathrm{C} / 36 \mathrm{~h}\right.$ com, aproximadamente, $100 \%$ UR do ar), em câmara de envelhecimento modelo "water jacketed". Em seguida, o material foi amostrado para as determinações preliminares utilizando-se do teste de germinação e do teor de água.

As sementes foram armazenadas em sacos de papel Kraft sob condições ambientais do laboratório, durante o período de realização do trabalho.

Germinação (TG) - Realizado com quatro repetições de 50 sementes, para cada tratamento, semeadas sobre papel toalha, umedecido com quantidade de água equivalente a três vezes o seu peso seco, e mantidas em câmara de germinação à temperatura constante de $18^{\circ} \mathrm{C}$, com oito horas de luz por dia. A contagem de plântulas normais foi efetuada no sétimo dia após a instalação do teste, considerando-se os critérios estabelecidos pelas Regras para Análise de Sementes (Brasil, 1992).

Teor de água (TA) - Determinado pelo método da estufa a $105 \pm 3^{\circ} \mathrm{C}$, por 24 horas, utilizando-se duas amostras de cada lote, conforme as Regras para Análise de Sementes (Brasil, 1992). Os resultados foram expressos em porcentagem.

Condicionamento osmótico - Foi realizado com solução (0,35 molar) de manitol, que segundo Georghiou et al. (1983), não permite a germinação de sementes de alface durante a embebição.

O cálculo do potencial osmótico proporcionado pela solução de manitol foi efetuado utilizando-se a equação de Van't Hoff: $\Psi$ osm = - RTC, onde: $\Psi$ osm = potencial osmótico (atmosfera), $\mathrm{R}=$ constante geral dos gases $=0,082$ atm $L$ mol$^{-1}{ }^{\circ} \mathrm{K}^{-1}, \mathrm{~T}=$ temperatura $\left({ }^{\circ} \mathrm{k}\right), \mathrm{C}$ = concentração molal (mols de soluto/ $1000 \mathrm{~g}$ de água). Assim, o potencial osmótico da solução a $0,35 \mathrm{moL}$ de manitol à temperatura de $20^{\circ} \mathrm{C}(293 \mathrm{~K})$ é equivalente a 8,41 atmosferas, ou - 0,841 MPa.

O processo de condicionamento osmótico consistiu na imersão de amostras de 10 gramas de sementes em $150 \mathrm{~mL}$ de solução de manitol a $20^{\circ} \mathrm{C}$, na presença de luz e sem aeração forçada, durante $0,3,4$, 5 e 6 dias; em seguida, as sementes foram retiradas da solução, lavadas em água corrente e submetidas à secagem até atingirem o peso inicial.

Secagem e armazenamento das sementes - Após o condicionamento osmótico as sementes foram secas em estufa com circulação de ar, à temperatura de $32^{\circ} \mathrm{C}$ por 12 horas, como o indicado por Guedes (1979).

As avaliações foram realizadas após os períodos de armazenamento de 0,10, 20, 30, 60 e 90 dias após a secagem.

Análise estatística - $O$ efeito do condicionamento foi estudado separadamente para cada cultivar, seguindo um delineamento experimental inteiramente casualizado, com quatro repetições (germinação) em todas as avaliações, os dados foram analisados em esquema fatorial $2 \times 5 \times 6$ (dois níveis de vigor, cinco períodos de condicionamento osmótico e seis períodos de armazenamento). As médias foram comparadas pelo teste de Tukey a $5 \%$. Para a análise estatística não foram consideradas as avaliações preliminares das sementes.

\section{RESULTADOS E DISCUSSÃO}

Os dados obtidos (Tabela 1) nas determinações preliminares para avaliar a qualidade fisiológica inicial das sementes indicaram que o envelhecimento gerou lotes com dois níveis de vigor. Pôde ser observada, pelo teste de germinação uma diminuição da viabilidade com o envelhecimento artificial das sementes, sendo considerado de qualidade superior as sementes não envelhecidas.

Sementes não condicionadas e condicionadas por três dias não apresentaram diferença estatística no decorrer do armazenamento, mas ocorreu redução na germinação para sementes condicionadas por quatro, cinco e seis dias (Tabela 4). A redução foi independente do nível de viabilidade à medida que se aumentava o período de armazenamento (Tabela 3).

Sementes do cultivar Nabuco RS reduziram a porcentagem de germinação com o aumento do período de condicionamento que foram submetidas, e de maneira mais drástica para sementes com alta viabilidade (Tabela 5). Esses dados comprovam as observações feitas por Heydecker \& Coolbear (1977), de que os lotes com qualidade fisiológica diferente, respondem diferentemente ao condicionamento osmótico.

Para sementes com alta viabilidade não houve diferença estatística para o material armazenado dos dez ao noventa dias, porém as sementes com baixa viabilidade a porcentagem de germinação diminuiu com o decorrer dos dias (Tabela 6). 
Tabela 1 - Germinação e o teor de água obtidos nas determinações preliminares, após o envelhecimento artificial.

\begin{tabular}{lccc}
\hline \multirow{2}{*}{ Cultivar } & \multicolumn{2}{c}{ Viabilidade } & \multirow{2}{*}{ Teor de água inicial } \\
\cline { 2 - 3 } & Alta (sem envelhecimento) & Baixa (com envelhecimento) & \\
\hline Mesa 659 & 95 & 42 & 5,7 \\
Nabuco RS & 100 & 37 & 7,3 \\
Verônica & 94 & 46 & 9,3 \\
\hline
\end{tabular}

Para os cultivares Mesa 659 e Nabuco RS a qualidade fisiológica das sementes dos diferentes tratamentos decresceu com o decorrer do armazenamento, ocorrendo uma possível reversão do condicionamento, ou mesmo deterioração das sementes em função do período de armazenamento. Constatação similar foi verificada por Tarquis \& Bradford (1992). Neste aspecto, McDonald (1999) relata que um dos pontos mais críticos da técnica do condicionamento osmótico de sementes é determinar o período de duração que se estende os benefícios do condicionamento durante 0 armazenamento.

Para o cultivar Nabuco RS não houve interação entre períodos de armazenamento versus o condicionamento osmótico das sementes.

Sementes de lotes de alta e de baixa viabilidade, quando submetidas ao condicionamento osmótico apresentaram respostas diferentes quanto à porcentagem de germinação, porém não se verificou efeito benéfico do condicionamento das sementes. Independentemente do nível de vigor das sementes, os maiores valores para germinação de sementes do cultivar Nabuco RS ocorreram para as sementes que não foram submetidas ao condicionamento osmótico. No caso desse cultivar, o condicionamento osmótico das sementes, mesmo por três dias, proporcionou reduções significativas na germinação.

O condicionamento osmótico de sementes dos cultivares Mesa 659 e Nabuco RS não melhoram o desempenho germinativo, sendo portanto, inviável nos períodos testados, para esses cultivares. O osmocondicionamento não beneficiou a performance das sementes de alface. Resultados semelhantes foi observado para sementes de ervilha por Liming et al., (1992) citado por McDonald, (1999).

Reduções na germinação, quando submetidas ao condicionametno osmótico com manitol, pode ser devido, este ser um álcool hexanhídrico de fórmula $\mathrm{C}_{6} \mathrm{H}_{14} \mathrm{O}_{6}$, podendo penetrar nas sementes durante a germinação, mostrando inclusive, fitotoxicidade (Slavik, 1974); opiniões semelhantes foram emitidas por Nabors \& Lang (1971).

As médias obtidas para as interações envolvendo níveis de viabilidade versus período de condicionamento osmótico, germinação em função dos períodos de armazenamento após o condicionamento osmótico e períodos de armazenamento após o
Tabela 2 - Germinação de sementes de alface, cultivar Mesa 659 e desdobramento das interações entre níveis de viabilidade e períodos de condicionamento osmótico.

\begin{tabular}{|c|c|c|}
\hline \multirow{2}{*}{ Período de Condicionamento } & \multicolumn{2}{|c|}{ Viabilidade } \\
\hline & Alta & Baixa \\
\hline dias & ----------- & ---------- \\
\hline 0 & $93 \mathrm{~A}^{1}$ & $75 \mathrm{~A} \mathrm{~b}$ \\
\hline 3 & $81 \mathrm{~B} \mathrm{a}$ & $70 \mathrm{~B} \mathrm{~b}$ \\
\hline 4 & $46 \mathrm{Cb}$ & $53 \mathrm{C} \mathrm{a}$ \\
\hline 5 & $28 \mathrm{D} \mathrm{b}$ & $42 \mathrm{D} a$ \\
\hline 6 & $28 \mathrm{D} \mathrm{b}$ & $47 \mathrm{D}$ a \\
\hline
\end{tabular}

${ }^{1}$ Médias seguidas pela mesma letra maiúscula na coluna e minúscula na linha, não diferem pelo teste de Tukey a $5 \%$.

Tabela 3 - Germinação de sementes de alface, cultivar Mesa 659 e desdobramento das interações entre níveis de viabilidade e períodos de armazenamento após o condicionamento osmótico.

\begin{tabular}{|c|c|c|}
\hline \multirow{2}{*}{ Período de Armazenamento } & \multicolumn{2}{|c|}{ Viabilidade } \\
\hline & Alta & Baixa \\
\hline dias & \multicolumn{2}{|c|}{ 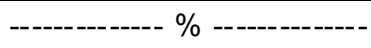 } \\
\hline 0 & $64 \mathrm{Aa}^{1}$ & $67 \mathrm{Aa}$ \\
\hline 10 & $52 \mathrm{BCb}$ & $60 \mathrm{ABa}$ \\
\hline 20 & $57 \mathrm{ABa}$ & $58 \mathrm{BCa}$ \\
\hline 30 & $47 \mathrm{Ca}$ & $47 \mathrm{Da}$ \\
\hline 60 & $62 \mathrm{Aa}$ & $55 \mathrm{BCb}$ \\
\hline 90 & $49 \mathrm{Ca}$ & $51 \mathrm{CDa}$ \\
\hline
\end{tabular}

${ }^{1}$ Médias seguidas pela mesma letra maiúscula na coluna e minúscula na linha, não diferem pelo teste de Tukey a $5 \%$.

condicionamento osmótico versus períodos de condicionamento osmótico, do cultivar Verônica, encontra-se respectivamente nas Tabelas 7, 8 e 9.

Tanto as sementes de alta viabilidade quanto as de baixa, não apresentaram diferenças significativas entre os períodos de condicionamento, exceto sementes de baixa viabilidade, com seis dias de condicionamento (Tabela 7). Para este cultivar em todos os períodos de condicionamento as sementes de alta viabilidade apresentaram comportamento germinativo superior em relação as de baixa (Tabela 7 ). 
Tabela 4 - Germinação de sementes de alface, cultivar Mesa 659 e desdobramento das interações entre períodos de armazenamento após o condicionamento osmótico e períodos de condicionamento.

\begin{tabular}{|c|c|c|c|c|c|c|}
\hline \multirow{2}{*}{ Período de Condicionamento } & \multicolumn{6}{|c|}{ Período de armazenamento (dias) } \\
\hline & 0 & 10 & 20 & 30 & 60 & 90 \\
\hline dias & ----------- & ------ & 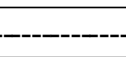 & 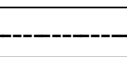 & ------ & -------- \\
\hline 0 & $89 \mathrm{Aab}^{1}$ & $92 \mathrm{Aa}$ & $88 \mathrm{Aab}$ & $77 \mathrm{Abc}$ & $76 \mathrm{Ac}$ & $82 \mathrm{Aabc}$ \\
\hline 3 & $79 \mathrm{Aa}$ & $69 \mathrm{Ba}$ & $73 \mathrm{Ba}$ & $70 \mathrm{Aa}$ & $80 \mathrm{Aa}$ & $70 \mathrm{Ba}$ \\
\hline 4 & $59 \mathrm{Ba}$ & $44 \mathrm{Cbc}$ & $54 \mathrm{Cab}$ & $38 \mathrm{Bc}$ & $61 \mathrm{Ba}$ & $43 \mathrm{Cbc}$ \\
\hline 5 & $51 \mathrm{Ba}$ & $39 \mathrm{Cb}$ & $36 \mathrm{Dbc}$ & $24 \mathrm{Ccd}$ & $36 \mathrm{Cbc}$ & $24 \mathrm{Dcd}$ \\
\hline 6 & $50 \mathrm{Ba}$ & $38 \mathrm{Cb}$ & $38 \mathrm{Db}$ & $26 \mathrm{Cc}$ & $42 \mathrm{Cab}$ & $32 \mathrm{Dbc}$ \\
\hline
\end{tabular}

${ }^{1}$ Médias seguidas pela mesma letra maiúscula na coluna e minúscula na linha, não diferem pelo teste de Tukey a $5 \%$.

Tabela 5 - Germinação de sementes de alface, cultivar Nabuco RS e desdobramento das interações entre níveis de viabilidade e períodos de condicionamento osmótico.

\begin{tabular}{ccc}
\hline Período de & \multicolumn{2}{c}{ Viabilidade } \\
\cline { 2 - 3 } Condicionamento & Alta & Baixa \\
\hline dias & $95 \mathrm{Aa}^{1}$ & $74 \mathrm{Ab}$ \\
0 & $23 \mathrm{Bb}$ & $37 \mathrm{Ba}$ \\
3 & $20 \mathrm{Bb}$ & $24 \mathrm{Ca}$ \\
4 & $11 \mathrm{Cb}$ & $19 \mathrm{Da}$ \\
5 & $8 \mathrm{Cb}$ & $14 \mathrm{Da}$ \\
\hline
\end{tabular}

${ }^{1}$ Médias seguidas pela mesma letra maiúscula na coluna e minúscula na linha, não diferem pelo teste de Tukey a $5 \%$.

Tabela 6 - Germinação de sementes de alface, cultivar Nabuco RS e desdobramento das interações entre níveis de viabilidade e períodos de armazenamento após o condicionamento osmótico .

\begin{tabular}{|c|c|c|}
\hline \multirow{2}{*}{$\begin{array}{c}\text { Perío do de } \\
\text { armazenamento }\end{array}$} & \multicolumn{2}{|c|}{ Viabilidade } \\
\hline & Alta & Baixa \\
\hline dias & ----------------- \% & ----------------- \\
\hline 0 & $36 A b^{1}$ & $39 \mathrm{ABa}$ \\
\hline 10 & $34 \mathrm{ABb}$ & $40 \mathrm{Aa}$ \\
\hline 20 & $31 \mathrm{ABa}$ & $34 \mathrm{BCa}$ \\
\hline 30 & $28 \mathrm{Bb}$ & $32 \mathrm{Ca}$ \\
\hline 60 & $30 \mathrm{Ba}$ & $29 \mathrm{CDa}$ \\
\hline 90 & $28 \mathrm{Ba}$ & $24 \mathrm{Db}$ \\
\hline
\end{tabular}

${ }^{1}$ Médias seguidas pela mesma letra maiúscula na coluna e minúscula na linha, não diferem pelo teste de Tukey a $5 \%$.

O período de armazenamento de 30 dias foi o que apresentou uma pequena redução da germinação, sendo diferente estatisticamente dos períodos de 10 e 20 dias (Tabela 8). Não houve interação significativa entre o período de armazenamento deste cultivar após o condicionamento osmótico e os níveis de viabilidade, sendo feita apenas a comparação das médias para a germinação independente viabilidade.
Tabela 7 - Germinação de sementes de alface, cultivar Verônica e desdobramento das interações entre níveis de viabilidade e períodos de condicionamento osmótico.

\begin{tabular}{ccc}
\hline \multirow{2}{*}{$\begin{array}{c}\text { Período de } \\
\text { Condicionamento }\end{array}$} & \multicolumn{2}{c}{ Viabilidade } \\
\cline { 2 - 3 } dias & Condicionamento & Alta \\
\hline 0 & $98 \mathrm{Aa}^{1}$ & $94 \mathrm{Ab}$ \\
3 & $98 \mathrm{Aa}$ & $95 \mathrm{Ab}$ \\
4 & $97 \mathrm{Aa}$ & $95 \mathrm{Ab}$ \\
5 & $97 \mathrm{Aa}$ & $94 \mathrm{Ab}$ \\
6 & $97 \mathrm{Aa}$ & $90 \mathrm{Bb}$ \\
\hline
\end{tabular}

${ }^{1}$ Médias seguidas pela mesma letra maiúscula na coluna e minúscula na linha, não diferem pelo teste de Tukey a $5 \%$.

Tabela 8 - Germinação de sementes de alface, cultivar Verônica, em função dos períodos de armazenamento após o condicionamento osmótico.

\begin{tabular}{cc}
\hline Período de armazenamento & Germinação \\
\hline dias & $\%$ \\
0 & $95 \mathrm{AB}^{1}$ \\
10 & $96 \mathrm{~A}$ \\
20 & $97 \mathrm{~A}$ \\
30 & $92 \mathrm{~B}$ \\
60 & $95 \mathrm{AB}$ \\
90 & $95 \mathrm{AB}$ \\
\hline
\end{tabular}

${ }^{1}$ Médias seguidas pela mesma letra maiúscula na coluna, não diferem pelo teste de Tukey a $5 \%$.

Para o cultivar Verônica, o condicionamento osmótico das sementes manteve o padrão de germinação das mesmas em todos os períodos de armazenamento, para todos períodos de condicionamento, exceto no caso de sementes condicionadas por seis dias e avaliadas em seguida, e também para sementes condicionadas por cinco e seis dias e armazenadas por 30 dias (Tabela 9). 
Tabela 9 - Germinação de sementes de alface, cultivar Verônica e desdobramento das interações entre períodos de armazenamento após o condicionamento osmótico e períodos de condicionamento.

\begin{tabular}{|c|c|c|c|c|c|c|}
\hline \multirow{2}{*}{ Período de Condicionamento } & \multicolumn{6}{|c|}{ Perío do de armazenamento (dias) } \\
\hline & 0 & 10 & 20 & 30 & 60 & 90 \\
\hline dias & ----------- & ------- & ------ & ---------- & --------- & --------- \\
\hline 0 & $98 \mathrm{Aa}^{1}$ & $97 \mathrm{Aa}$ & $97 \mathrm{Aa}$ & $92 \mathrm{ABa}$ & $94 \mathrm{Aa}$ & $96 \mathrm{Aa}$ \\
\hline 3 & $96 \mathrm{Aa}$ & $96 \mathrm{Aa}$ & $97 \mathrm{Aa}$ & $97 \mathrm{Aa}$ & $97 \mathrm{Aa}$ & $96 \mathrm{Aa}$ \\
\hline 4 & $96 \mathrm{Aa}$ & $97 \mathrm{Aa}$ & $98 \mathrm{Aa}$ & $96 \mathrm{ABa}$ & $96 \mathrm{Aa}$ & $95 \mathrm{Aa}$ \\
\hline 5 & $97 \mathrm{Aa}$ & $96 \mathrm{Aa}$ & $98 \mathrm{Aa}$ & $90 \mathrm{BCb}$ & $96 \mathrm{Aa}$ & $97 \mathrm{Aa}$ \\
\hline 6 & $90 \mathrm{Bbc}$ & $96 \mathrm{Aab}$ & $97 \mathrm{Aa}$ & $89 \mathrm{Cc}$ & $92 \mathrm{Aabc}$ & $93 \mathrm{Aabc}$ \\
\hline
\end{tabular}

${ }^{1}$ Médias seguidas pela mesma letra maiúscula na coluna e minúscula na linha, não diferem pelo teste de Tukey a $5 \%$.

\section{REFERÊNCIAS BIBLIOGRÁFICAS}

BRADFORD, K.J. Manipulation of seed water relations via osmotic priming to improve germination under stress conditions. HortScience, v.21, p.1105-1112,1986.

BRASIL. Ministério da Agricultura. Regras para análise de sementes. Brasília: SNAD; DNPV; CLAV, 1992. 365p.

EIRA, M.T.S.; MARCOS FILHO, J. Condicionamento osmótico de sementes de alface: I. Efeitos sobre a germinação. Revista Brasileira de Sementes, v.12, p.9-27, 1990.

GUEDES, A.C. The use of seed priming to hasten germination of lettuce seeds at high temperature. Gainesville, 1979. 169p. Thesis (Ph.D.) - University of Florida.

GEORGHIOU, K.; PSARAS, G.; MITRAKOS, K. Lettuce endosperm structural changes during germination under different light, temperature, and hydration conditions. Botanical Gazette, v.144, p.207-211, 1983.

HEYDECKER, W.; GIBBINS, B.M. The priming of seeds. Acta Horticulturae, v.83, p.213-223, 1978.

HEYDECKER, W.; COOLBEAR, P. Seed treatments for improved performance survey and attempted prognosis. Seed Science and Technology, v.5, p.353-425, 1977.

KHAN, A.A.; TAO, K.L.; KNYPL, J.S.; BORKOWSKA, B.; LOY, E.P. Osmotic conditioning of seed: physiological and biochemical changes. Acta Horticulturae, v.83, p.267-278, 1978.
KHAN, A.A. Preplant physiological seed conditioning. Horticultural Review, v.13, p.131-181, 1992.

McDONALD, M.B. Seed quality assessment. Seed Science Research, v.8, p.265-275, 1998.

McDONALD, M.B. Seed deterioration: physiology, repair and assessment. Seed Science and Technology, v.27, p.177237, 1999.

NABORS, M.W.; LANG, A. The growth physics and water relations of red-light-indiced germination in lettuce seeds: I. Embryos germinating in osmoticum. Planta, v.101, p.1-25, 1971.

SLAVIK, B. Methods of studing plant water relations. New York: springer-Verlag, 1974. 449p. (Ecological Studies, 9).

TARQUIS, A.M.; BRADFORD, K.J. Prehydration and priming treatments that advance germination also increase the rate of deterioration of lettuce seed. Journal of Experimental Botany, v.43, p.307-317, 1992.

$\overline{\text { Recebido em } 15} .09 .00$ 